\title{
Survival of Burkholderia pseudomallei and Pathogenic Leptospira in Cola, Beer, Energy Drinks, and Sports Drinks
}

\author{
Vanaporn Wuthiekanun, ${ }^{1}$ Premjit Amornchai, ${ }^{1 \star}$ Sayan Langla, ${ }^{1}$ Nicholas J. White, ${ }^{1,2}$ Nicholas P. J. Day, ${ }^{1,2}$ and \\ Direk Limmathurotsakul ${ }^{1,2,3}$ \\ ${ }^{1}$ Mahidol Oxford Tropical Medicine Research Unit, Faculty of Tropical Medicine, Mahidol University, Bangkok, Thailand; ${ }^{2}$ Centre for Tropical \\ Medicine and Global Health, University of Oxford, Oxford, United Kingdom; ${ }^{3}$ Department of Tropical Hygiene, Faculty of Tropical Medicine, \\ Mahidol University, Bangkok, Thailand
}

\begin{abstract}
Burkholderia pseudomallei and pathogenic Leptospira in contaminated drinking water can cause melioidosis and leptospirosis, respectively. Here, we evaluated their survival in beverages. We mixed six isolates (three isolates per organism) in four beverages (Coca-Cola ${ }^{\circledR}$, Red Bull $^{\circledR}$, Singha $^{\circledR}$ beer, and Gatorade ${ }^{\circledR}$ ) and distilled water as the control at two final concentrations $\left(1 \times 10^{7}\right.$ colony-forming units [CFU]/mL and $\left.1 \times 10^{3} \mathrm{CFU} / \mathrm{mL}\right)$. The solution was kept at two temperatures $\left(37^{\circ} \mathrm{C}\right.$ and $\left.4^{\circ} \mathrm{C}\right)$. At $4^{\circ} \mathrm{C}$ and at the high concentration, pathogenic Leptospira survived in Coca-Cola ${ }^{\circledR}$ up to 3 minutes and in Singha, Red Bull ${ }^{\circledR}$, and Gatorade up to 15 minutes, whereas $B$. pseudomallei survived in these beverages up to 8 hours, and 14,14 , and 28 days, respectively. The survival time of both organisms was shorter at $37^{\circ} \mathrm{C}(P=0.01)$ and at the lower concentration $(P=0.001)$. In conclusion, Leptospira can survive in some beverages for up to 15 minutes, whereas $B$. pseudomallei can survive in some beverages for up to 4 weeks.
\end{abstract}

Burkholderia pseudomallei is a Gram-negative environmental bacterium and the causative organism of melioidosis, which kills an estimated 89,000 people per year worldwide. ${ }^{1}$ Humans acquire melioidosis by ingestion, inhalation, or skin inoculation. ${ }^{2,3} B$. pseudomallei is capable of surviving hard environmental conditions, including prolonged nutrient deficiency in distilled water for more than 16 years. ${ }^{4}$ Two outbreaks of melioidosis due to contaminated water supplies have been reported in Australia, ${ }^{2}$ and melioidosis caused by $B$. pseudomallei in drinking water have also been reported in Thailand. ${ }^{3}$

Pathogenic Leptospira spp. is a spirochete bacterium and the causative organism of leptospirosis, which kills an estimated 58,900 people per year worldwide. ${ }^{5}$ Humans acquire leptospirosis by drinking or contacting with water, soil, or food contaminated with the urine of infected animals. Pathogenic Leptospira remain viable in fresh water for up to 20 months. ${ }^{6}$ A number of outbreaks of leptospirosis have been linked to contaminated drinking water supply in multiple countries, including Chile, India, and Italy. ${ }^{7-9}$ Although B. pseudomallei and Leptospira spp. could survive in water for a long period of time, it is unclear how long both organisms can survive in common commercial drinks. If containers of drinks have holes or tears, drinks are contaminated with soil (and B. pseudomallei) or rat urine (and Leptospira spp.), and the organisms can survive for a long period of time, consuming contaminated drinks could lead to infection. In this study, we evaluated survival of $B$. pseudomallei and Leptospira spp. in four beverages at $4^{\circ} \mathrm{C}$ and $37^{\circ} \mathrm{C}$.

Isolates used in our study included one environmental B. pseudomallei isolate (E8), ${ }^{10}$ two clinical B. pseudomallei isolates (NR-9910 and NR-8071), and three pathogenic Leptospira isolates (L. interrogans serovar Autumnalis [NR-20161], L. kirschnerii serovar Grippotyphosa [NR-20327], and L. interrogans serovar Pyrogenes [NR-20157]). ${ }^{11,12}$ Survival of these isolates were evaluated in a cola drink (Coca-Cola ${ }^{\circledR}$ original), beer (Singha ${ }^{\circledR}$ original), an energy drink (Red Bull ${ }^{\circledR}$ Extra), and a sports drink (Gatorade ${ }^{\circledR}$ lemon lime) with distilled water used as the control.

\footnotetext{
*Address correspondence to Premjit Amornchai, Mahidol-Oxford Tropical Medicine Research Unit, Faculty of Tropical Medicine, Mahidol University, 420/6 Rajvithi Rd., Bangkok 10400, Thailand. E-mail: kung@tropmedres.ac
}

B. pseudomallei isolates were recovered from frozen vials stored at $-80^{\circ} \mathrm{C}$, transferred to Columbia agar, and incubated at $37^{\circ} \mathrm{C}$ for 24 hours. B. pseudomallei colonies were harvested, suspended into sterile water, and adjusted to obtain a concentration of about $1 \times 10^{8}$ colony-forming units (CFU)/ $\mathrm{mL}$. Leptospira isolates were recovered from Leptospira Vanaporn Wuthiekanun (LVW) agar stored at room temperature $\left(25-30^{\circ} \mathrm{C}\right) .^{13}$ Each Leptospira strain was subcultured to Ellinghausen and McCullough modified Johnson and Harris (EMJH) broth and adjusted to an optical density of 0.32 at $420 \mathrm{~nm}$ to obtain a concentration of about $1 \times 10^{8} \mathrm{CFU} / \mathrm{mL}$.

We evaluated the survival of the two organisms in four beverages with two different final concentrations and at two temperatures. Each isolate, at concentrations of about $1 \times 10^{8}$ and $1 \times 10^{4} \mathrm{CFU} / \mathrm{mL}$ in $0.3 \mathrm{~mL}$ of sterile water for $B$. pseudomallei and EMJH broth for Leptospira, was inoculated into $2.7 \mathrm{~mL}$ (total $3 \mathrm{~mL}$ ) of each beverage to obtain final concentrations of about $1 \times 10^{7}$ and $1 \times 10^{3} \mathrm{CFU} / \mathrm{mL}$. The solutions were mixed and kept in sterile 5-mL tubes. One set of the high concentration $\left(1 \times 10^{7} \mathrm{CFU} / \mathrm{mL}\right)$ and one set of the low concentration $\left(1 \times 10^{3}\right.$ $\mathrm{CFU} / \mathrm{mL}$ ) were kept at $4^{\circ} \mathrm{C}$, and another set each of the low concentration and high concentration were kept at $37^{\circ} \mathrm{C}$. The low and high temperatures were chosen to represent drinks kept in refrigerators and tropical climates, respectively. A pilot study was initially performed to approximate the survival time of both organisms in all drinks at both temperatures at 1 hour and 1 day. For the organism that did not survive up to 1 hour, the study was repeated and survival of organisms was reevaluated at $1,3,5,15,30$, and 60 minutes. For the organism that survived up to 1 hour but not up to 1 day, survival of organisms was reevaluated at 1, 2, 4, 6, 8, and 24 hours. For the organism that survived up to 1 day, survival of organisms was reevaluated at 1 , $3,5,7,10,12,14,21,28$, and 35 days. The study was performed in duplicate.

The survival and colony count of $B$. pseudomallei from beverages at the high concentration was assessed by collecting an aliquot of $100 \mu \mathrm{L}$ and making four 10-fold dilutions with sterile distilled water (from 1:100, 1:1,000, and 1:10,000 to $1: 100,000)$. Then an aliquot $(100 \mu \mathrm{L})$ of each 10 -fold dilution was spread on a whole Columbia agar plate using a rotary plater. For B. pseudomallei from beverages at the low 

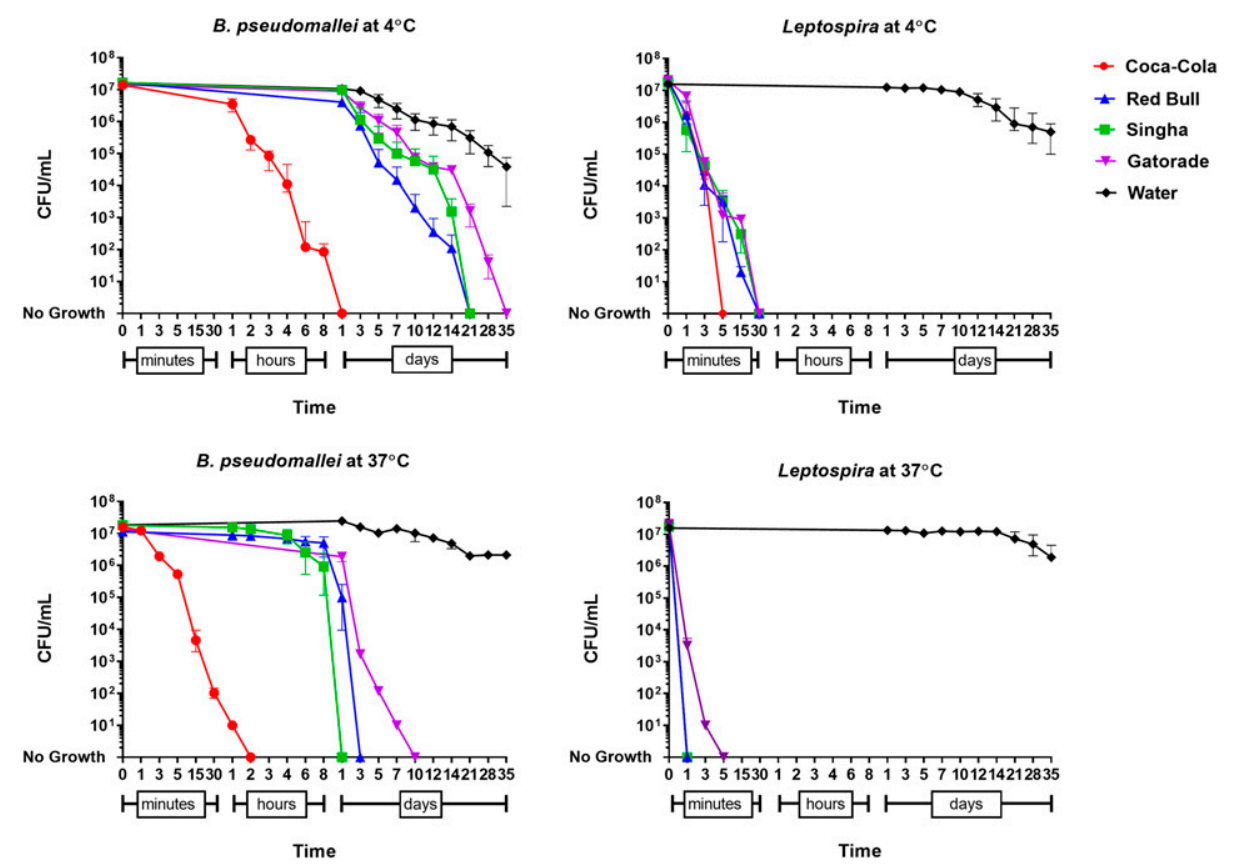

FlgURE 1. Survival of Burkholderia pseudomallei and pathogenic Leptospira in Coca-Cola, Red Bull, Singha beer, Gatorade, and distilled water at the high final concentration $\left(1 \times 10^{7} \mathrm{CFU} / \mathrm{mL}\right)$. This figure appears in color at www.ajtmh.org.

concentration, an aliquot of $100 \mu \mathrm{L}$ was dropped and spread directly on a whole Columbia agar plate. Another $100 \mu \mathrm{L}$ from each beverage was directly inoculated into $3 \mathrm{~mL}$ of Tryptic soya broth and incubated in air at $37^{\circ} \mathrm{C}$ for 24 hours; consequently, an aliquot of $10 \mu \mathrm{L}$ of surface broth was streaked onto a half of the Columbia agar plate. All Columbia agar plates were incubated in air at $37^{\circ} \mathrm{C}$ and inspected daily. A colony count was performed on day 4 . The survival and colony count of Leptospira was assessed by spreading an aliquot of $100 \mu \mathrm{L}$ onto a whole LVW agar plate. All LVW agar plates were incubated at $30^{\circ} \mathrm{C}$ in $\mathrm{CO}_{2}$ for 2 days and then in air at $30^{\circ} \mathrm{C}$ for 4 weeks in total. Colony counts were performed weekly for 4 weeks with the naked eye. ${ }^{11}$ Another $100 \mu \mathrm{L}$ was inoculated into $1 \mathrm{~mL}$ of EMJH broth and incubated at $30^{\circ} \mathrm{C}$. Survival of
A

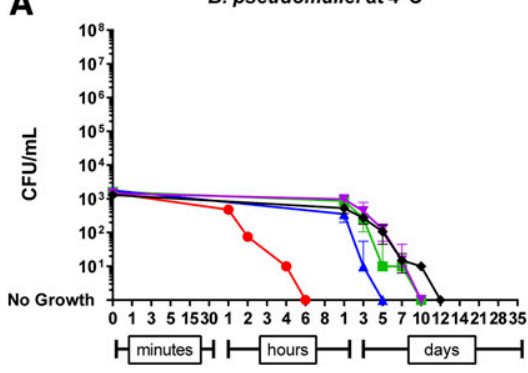

Time

C

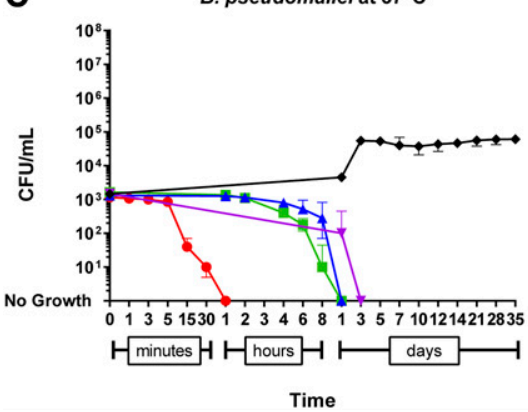

B

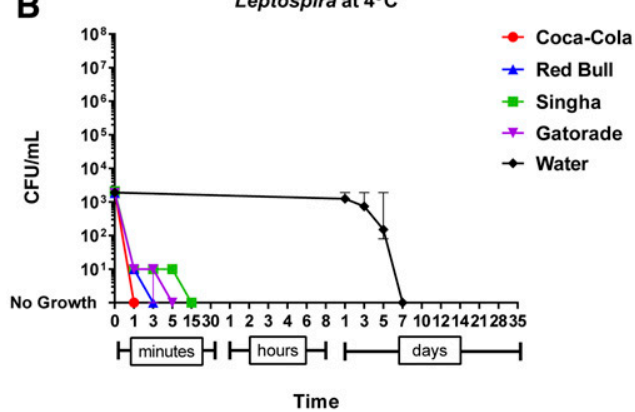

D

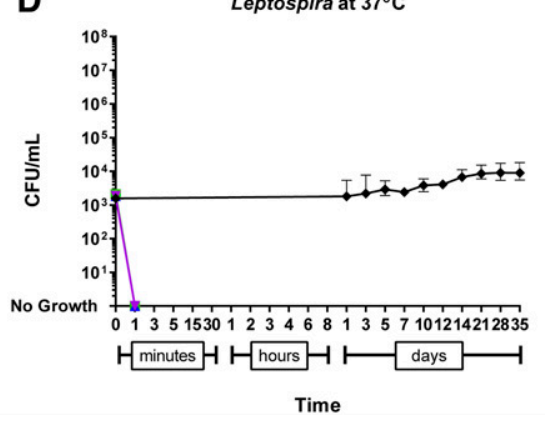

FIGURE 2. Survival of Burkholderia pseudomallei and pathogenic Leptospira in Coca-Cola, Red Bull, Singha beer, Gatorade, and distilled water at the low final concentration $\left(1 \times 10^{3} \mathrm{CFU} / \mathrm{mL}\right)$. This figure appears in color at www.ajtmh.org. 
Leptospira in EMJH was detected by using a dark-field microscope weekly for 4 weeks.

Each beverage was evaluated for $\mathrm{pH}$ at $4^{\circ} \mathrm{C}, 25^{\circ} \mathrm{C}$, and $37^{\circ} \mathrm{C}$ using $\mathrm{pH}$ meters (Mettler Toledo, Greifensee, Schweizerland). Univariable and multivariable Cox proportional hazard models were used to evaluate the conditions associated with time to culture negative of the organisms.

We found that time to culture negativity was different among beverages $(P<0.001)$. The shortest duration of survival was observed in Coca-Cola for both organisms in all conditions (Figures 1 and 2). We found that $B$. pseudomallei survived longer than Leptospira in all conditions $(P<0.001$; Table 1$)$. Both organisms survived longer in the high concentration $(1 \times$ $\left.10^{7} \mathrm{CFU} / \mathrm{mL}\right)$ than the low concentration $\left(1 \times 10^{3} \mathrm{CFU} / \mathrm{mL}\right)(P=$ 0.001 ; Table 1). We found that both organisms survived longer in the four beverages at $4^{\circ} \mathrm{C}$ than at $37^{\circ} \mathrm{C}$ except in distilled water, in which both organisms survived for a shorter duration at $4^{\circ} \mathrm{C}$ than at $37^{\circ} \mathrm{C}$. There was no difference in survival times between strains of $B$. pseudomallei $(P>0.99)$ and between strains of Leptospira $(P>0.99)$ evaluated.

At $4^{\circ} \mathrm{C}$ and at the higher inoculum concentration, pathogenic Leptospira survived briefly in Coca-Cola, Red Bull, Singha, and Gatorade (up to 3, 15, 15, and 15 minutes, respectively; Figure 1B). By contrast, B. pseudomallei survived in these beverages in the same condition for up to 8 hours, 14 days, 14 days, and 28 days, respectively (Figure 1A). At $37^{\circ} \mathrm{C}$, Leptospira spp. died in all four beverages within 5 minutes (Figures 1D and 2D).

The pH of Coca-Cola, Red Bull, Singha beer, Gatorade, and distilled water evaluated was $2.71,3.72,4.46,3.37$, and 6.98 (at $4^{\circ} \mathrm{C}$ ); $2.50,3.56,4.30,3.13$, and 6.85 (at $25^{\circ} \mathrm{C}$ ); and 2.44 , $3.51,4.26,3.08$, and 6.49 (at $37^{\circ} \mathrm{C}$ ), respectively.

In this study, we demonstrated that pathogenic Leptospira organisms can survive in some beverages for up to 15 minutes, whereas $B$. pseudomallei can survive in some beverages for up to 4 weeks, particularly when the beverages are kept in a refrigerator at $4^{\circ} \mathrm{C}$. This shows that people can get infected from contaminated cold drinks. A previous case report from Belgium found that drinking a can of soft drink with dried rat's urine contaminating the top of the can could be the cause of leptospirosis and suggested washing cans before consumption. ${ }^{14}$
Presumably, the amount of bacteria contaminating the outside of the containers in those cases could not be killed by cold drinks within seconds of drinking. To reduce the risk of getting infections, we strongly suggest that people should always inspect containers of the drink or water; make sure that they have no holes, tears, or openings; and wash them carefully before drinking.

People should not be frightened by potential fake news about poor storage of drinks or deliberate contamination of the top of the can with bacteria or rat's urine. B. pseudomallei is a Tier 1 select agent and controlled by local and international regulations. ${ }^{2}$ Leptospira spp. is difficult to grow and maintain and available only in a limited number of laboratories worldwide. ${ }^{5}$ The prevalence of captured rats being infected with leptospirosis is low even in leptospirosis-endemic areas. ${ }^{7-9}$ Therefore, the chance of deliberate release is low. For any potential fake news in the future, people should look for rumour-countering warnings, and expert organizations should correct any misinformation released. ${ }^{15,16}$ Nonetheless, the risk of accidental occurrence is not zero.

It is possible that the main factors in beverages associated with shorter duration of survival is the degree of acidity. CocaCola has the lowest $\mathrm{pH}$ and is associated with the shortest duration of survival in both organisms. This is supported by the previous studies showing that $B$. pseudomallei can survive in normal saline at $\mathrm{pH} 2.0$ for 1 day and at 3.0 for 7 days, ${ }^{17}$ and Leptospira spp. is commonly observed in soil and water with $\mathrm{pH}$ around 5.5 and $7.6 .^{18}$ The relatively shorter duration of B. pseudomallei survival at $37^{\circ} \mathrm{C}$ in Coca-Cola (less than 2 hours; pH 2.44) and in Red Bull and Singha beer (less than 3 days; $\mathrm{pH}$ from 3.51 to 4.26 ) observed in this study could be due to other ingredients such as preservatives, chemical additive, phosphoric acid, caffeine, and sodium citrate in the drinks. ${ }^{19-21}$

The longer survival time of $B$. pseudomallei than that of pathogenic Leptospira spp. is likely to be because $B$. pseudomallei is an environmental organism, whereas the main reservoirs of pathogenic Leptospira are rodents. Therefore, pathogenic Leptospira are less equipped to survive in a wide range of conditions of soil and water than $B$. pseudomallei. ${ }^{2,3}$

It is interesting that both organisms survive longer at $4^{\circ} \mathrm{C}$ than at $37^{\circ} \mathrm{C}$ in all four beverages but shorter at $4^{\circ} \mathrm{C}$ than at

TABLE 1

Factors associated with time to culture negative of Burkholderia pseudomallei and pathogenic Leptospira in beverages and distilled water

\begin{tabular}{|c|c|c|c|c|}
\hline Condition ${ }^{*}$ & Crude hazard ratio $(95 \% \mathrm{Cl})$ & $P$-value & Adjusted hazard ratio $(95 \% \mathrm{Cl})$ & $P$-value \\
\hline \multicolumn{5}{|l|}{ Organism } \\
\hline $\begin{array}{l}\text { Pathogenic Leptospira } \\
\text { B. pseudomallei }\end{array}$ & $\begin{array}{c}1.0 \\
0.42(0.28-0.63)\end{array}$ & $<0.001$ & $0.01(<0.01-0.05)$ & $<0.001$ \\
\hline \multicolumn{5}{|l|}{ Final concentration } \\
\hline $\begin{array}{l}\text { Low }\left(1 \times 10^{3} \mathrm{CFU} / \mathrm{mL}\right) \\
\text { High }\left(1 \times 10^{7} \mathrm{CFU} / \mathrm{mL}\right)\end{array}$ & $\begin{array}{c}1.0 \\
0.67(0.45-1.00)\end{array}$ & 0.05 & $\begin{array}{c}1.0 \\
0.46(0.29-0.72)\end{array}$ & 0.001 \\
\hline \multicolumn{5}{|l|}{ Beverages } \\
\hline Distilled water & 1.0 & $<0.001$ & 1.0 & $<0.001$ \\
\hline Coca-Cola & $24.1(9.3-62.5)$ & & $2030.1(346.5-11,892.1)$ & \\
\hline Red Bull & $11.2(4.5-27.7)$ & & $600.7(115.8-3,115.2)$ & \\
\hline Singha beer & $10.2(4.1-25.3)$ & & $512.1(98.6-2,660.4)$ & \\
\hline Gatorade & $7.7(3.1-19.3)$ & & $354.9(69.5-1,811.3)$ & \\
\hline \multicolumn{5}{|l|}{ Temperature } \\
\hline $\begin{array}{l}37^{\circ} \mathrm{C} \\
4^{\circ} \mathrm{C}\end{array}$ & $\begin{array}{c}1.0 \\
0.58(0.45-1.00) \dagger\end{array}$ & 0.02 & $\begin{array}{c}1.0 \\
0.54(0.33-0.87)\end{array}$ & 0.01 \\
\hline
\end{tabular}

* Hazard ratio represents the ratio of time to culture negative compared with the baseline condition (for which HR $=1.0$ ) over time. An HR value of less than 1.0 indicates the time to culture negative was longer than the baseline condition, and vice versa.

† Excluding distilled water from the univariable analysis because both organisms survived in four beverages longer at $4^{\circ} \mathrm{C}$ than at $37^{\circ} \mathrm{C}$ except distilled water, in which both organisms survived for shorter duration at $4^{\circ} \mathrm{C}$ than at $37^{\circ} \mathrm{C}$ (Figures 1 and 2 ). 
$37^{\circ} \mathrm{C}$ in distilled water. At lower temperature, cell composition, chemical reactions, membrane lipid fluidity, proteins, growth phase, growth rates, and other factors may change. ${ }^{22}$ Those factors may increase survival time in the extreme conditions in the beverages but might not be able to support the growth of the organisms in distilled water at $4^{\circ} \mathrm{C}$ compared with tropical climates at $37^{\circ} \mathrm{C}$.

Our study has few limitations. We used culture to identify the survival of both organisms. We could not isolate the organisms at very low concentrations (e.g., $<10 \mathrm{CFU} / \mathrm{mL}$ ) or as viable but non-culturable cells (VBNCs).

Received December 20, 2019. Accepted for publication February 21, 2020.

Published online April 6, 2020.

Financial support: This work was supported by the Wellcome Trust (089275/Z/09/Z). D. L. was supported by a Wellcome Trust Public Health and Tropical Medicine Intermediate Fellowship (101103/Z/13/ Z).

Disclaimer: The funders had no role in study design, data collection and analysis, decision to publish, or preparation of the manuscript.

Authors' addresses: Vanaporn Wuthiekanun, Premjit Amornchai, and Sayan Langla, Mahidol-Oxford Tropical Medicine Research Unit, Faculty of Tropical Medicine, Mahidol University, Bangkok, Thailand, E-mails: lek@tropmedres.ac, kung@tropmedres.ac, and sayan@ tropmedres.ac. Nicholas J. White and Nicholas P. J. Day, MahidolOxford Tropical Medicine Research Unit, Faculty of Tropical Medicine, Mahidol University, Bangkok, Thailand, and Centre for Tropical Medicine and Global Health, University of Oxford, Oxford, United Kingdom, E-mails: nickwdt@tropmedres.ac and nickd@tropmedres.ac. Direk Limmathurotsakul, Mahidol-Oxford Tropical Medicine Research Unit, Faculty of Tropical Medicine, Mahidol University, Bangkok, Thailand, Centre for Tropical Medicine and Global Health, University of Oxford, Oxford, United Kingdom, and Department of Tropical Hygiene, Faculty of Tropical Medicine, Mahidol University, Bangkok, Thailand, E-mail: direk@tropmedres.ac.

This is an open-access article distributed under the terms of the Creative Commons Attribution (CC-BY) License, which permits unrestricted use, distribution, and reproduction in any medium, provided the original author and source are credited.

\section{REFERENCES}

1. Limmathurotsakul $D$ et al., 2016. Predicted global distribution of Burkholderia pseudomallei and burden of melioidosis. Nat Microbiol 1: 15008.

2. Wiersinga WJ, Virk HS, Torres AG, Currie BJ, Peacock SJ, Dance DAB, Limmathurotsakul D, 2018. Melioidosis. Nat Rev Dis Primers 4: 17107

3. Limmathurotsakul D et al., 2014. Melioidosis caused by Burkholderia pseudomallei in drinking water, Thailand, 2012. Emerg Infect Dis 20: 265-268.

4. Pumpuang A, Chantratita N, Wikraiphat C, Saiprom N, Day NP, Peacock SJ, Wuthiekanun V, 2011. Survival of Burkholderia pseudomallei in distilled water for 16 years. Trans $R$ Soc Trop Med Hyg 105: 598-600.

5. Costa F, Hagan JE, Calcagno J, Kane M, Torgerson P, MartinezSilveira MS, Stein C, Abela-Ridder B, Ko Al, 2015. Global morbidity and mortality of leptospirosis: a systematic review. PLoS Negl Trop Dis 9: e0003898.

6. Andre-Fontaine G, Aviat F, Thorin C, 2015. Waterborne leptospirosis: survival and preservation of the virulence of pathogenic leptospira spp. in fresh water. Curr Microbiol 71: 136-142.

7. Ramakrishnan R, Patel MS, Gupte MD, Manickam P, Venkataraghavan S, 2003. An institutional outbreak of leptospirosis in Chennai, South India. J Commun Dis 35: 1-8.

8. Munoz-Zanzi C, Mason MR, Encina C, Astroza A, Romero A, 2014. Leptospira contamination in household and environmental water in rural communities in southern Chile. Int J Environ Res Public Health 11: 6666-6680.

9. Cacciapuoti B, Ciceroni L, Maffei C, Di Stanislao F, Strusi P, Calegari L, Lupidi R, Scalise G, Cagnoni G, Renga G, 1987. A waterborne outbreak of leptospirosis. Am J Epidemiol 126: 535-545.

10. Wuthiekanun V, Smith MD, Dance DA, Walsh AL, Pitt TL, White NJ, 1996. Biochemical characteristics of clinical and environmental isolates of Burkholderia pseudomallei. J Med Microbiol 45: 408-412.

11. Wuthiekanun V et al., 2013. Rapid isolation and susceptibility testing of Leptospira spp. using a new solid medium, LVW agar. Antimicrob Agents Chemother 57: 297-302.

12. Wangroongsarb $P$ et al., 2007. Molecular typing of Leptospira spp. based on putative O-antigen polymerase gene (wzy), the benefit over 16S rRNA gene sequence. FEMS Microbiol Lett 271: 170-179.

13. Wuthiekanun V, Amornchai $P$, Langla S, Oyuchua M, Day NP, Limmathurotsakul D, 2014. Maintenance of leptospira species in leptospira Vanaporn Wuthiekanun agar. J Clin Microbiol 52: 4350-4352.

14. Kaur J, Lal R, 2009. Cold drink cans contaminated with rat urine can kill. Indian J Microbiol 49: 294.

15. Peters A, Tartari E, Lotfinejad N, Parneix P, Pittet D, 2018. Fighting the good fight: the fallout of fake news in infection prevention and why context matters. J Hosp Infect 100: 365-370.

16. Wang Y, McKee M, Torbica A, Stuckler D, 2019. Systematic literature review on the spread of health-related misinformation on social media. Soc Sci Med 240: 112552.

17. Tong S, Yang S, Lu Z, He W, 1996. Laboratory investigation of ecological factors influencing the environmental presence of Burkholderia pseudomallei. Microbiol Immunol 40: 451-453.

18. Barragan V, Olivas S, Keim P, Pearson T, 2017. Critical knowledge gaps in our understanding of environmental cycling and transmission of leptospira spp. Appl Environ Microbiol 83: e01190-e01217.

19. Whitney AK, Weir TL, 2015. Interaction of caffeine with the SOS response pathway in Escherichia coli. Gut Pathog 7: 21.

20. Sandlie I, Solberg K, Kleppe K, 1980. The effect of caffeine on cell growth and metabolism of thymidine in Escherichia coli. Mutat Res 73: 29-41.

21. Dotsey RP, Moser EAS, Eckert GJ, Gregory RL, 2017. Effects of cola-flavored beverages and caffeine on Streptococcus mutans biofilm formation and metabolic activity. J Clin Pediatr Dent 41: 294-299.

22. Berry ED, Foegeding PM, 1997. Cold temperature adaptation and growth of microorganisms. J Food Prot 60: 1583-1594. 